\title{
Desperdício de alimentos em cozinha escola de uma universidade pública: perspectivas de gestão e sustentabilidade
}

\author{
Food waste in school-kitchen at a public university: management and sustainability perspectives \\ Desperdicio de alimentos en una cocina-escuela de una universidad pública: perspectivas de gestión \\ y sostenibilidad
}

Recebido: 14/12/2021 | Revisado: 21/12/2021 | Aceito: 21/12/2021 | Publicado: 01/01/2022

\author{
Mayza Mayara Costa de Jesus \\ ORCID: https://orcid.org/0000-0002-5280-2908 \\ Universidade Federal da Bahia, Brasil \\ E-mail: maay_costa@hotmail.com \\ Simone Florentino de Souza \\ ORCID: https://orcid.org/0000-0002-0674-5033 \\ Universidade Federal da Bahia, Brasil \\ E-mail: simone_sic@hotmail.com \\ Elaine Janaína Linhares da Conceição \\ ORCID: https://orcid.org/0000-0002-5104-0622 \\ Universidade Federal da Bahia, Brasil \\ E-mail: elainejlc@hotmail.com \\ Laise Cedraz Pinto \\ ORCID: https://orcid.org/0000-0001-7470-7074 \\ Universidade Federal da Bahia, Brasil \\ E-mail: lcedraz@hotmail.com \\ Márcia Filgueiras Rebelo de Matos \\ ORCID: https://orcid.org/0000-0003-3769-9364 \\ Universidade Federal da Bahia, Brasil \\ E-mail: mfrmatos@ufba.br
}

\begin{abstract}
Resumo
As taxas de desperdício de alimentos no mundo são elevadas e ocorrem em toda a cadeia produtiva, inclusive em Unidades de Alimentação e Nutrição (UAN). A cozinha escola constitui UAN comum à rotina de ensino aprendizagem para a formação de profissionais relacionados à área de Alimentos e Bebidas. O presente artigo objetivou avaliar o desperdício de alimentos em uma cozinha escola dos cursos de Nutrição e Gastronomia de uma universidade pública da Bahia e propor estratégias para este controle. Os alimentos foram divididos em cinco grupos: frutas; hortaliças; ovos e laticínios; carnes e não perecíveis. A coleta de dados foi realizada a partir das planilhas de registros de excedentes e de controle de temperatura dos equipamentos nos anos de 2017 a 2019. O total global de desperdício no período avaliado foi de 121,3 kg, sendo que o grupo dos não-perecíveis obteve maior taxa (média de $19,2 \mathrm{~kg} / \mathrm{ano}$ ). Os três principais motivos de desperdício foram: produto fora do prazo de validade, deteriorado e com acondicionamento inadequado. Os dados do controle dos equipamentos do estoque frio indicaram alta variabilidade de temperatura e baixa manutenção. Visando reduzir o desperdício, discentes da universidade aplicaram técnicas de conservação e desenvolveram novos produtos, sendo estas estratégias capazes de promover a utilização de excedentes em outras aulas e possibilitar a redução da taxa de desperdício na UAN. Os resultados encontrados evidenciaram as causas das perdas na cozinha escola e apresentaram medidas para seu controle, ressaltando a importância de propostas de ensino aprendizagem que vêm contribuindo para a inovação e formação profissional.
\end{abstract}

Palavras-chave: Desperdício de alimentos; Aproveitamento integral de alimentos; Desenvolvimento de novos produtos; Gestão de materiais.

\footnotetext{
Abstract

Global rates of food waste are high and occur throughout the production chain, including Food and Nutrition Units (FNU). School-Kitchen is an FNU associated with routine teaching and learning for the training of professionals in the area of Food and Beverage. This study aimed to evaluate food waste in the school-kitchen at a public university in Bahia, Brazil, and to propose strategies for its control. Foods were classified into five groups: fruits; vegetables; eggs and dairy products; meat and non-perishables. Data collection was performed using spreadsheets recording excess food and temperature control of equipment registered in 2017 to 2019. The total food waste in the period evaluated was $121.3 \mathrm{~kg}$ and non-perishable group had the highest rate (mean of $19.2 \mathrm{~kg} / \mathrm{year}$ ). The three main causes of waste
} 
were: expired shelf life, spoilage and inadequate storage temperature. Cold storage equipment indicated high temperature variability and low maintenance. Aiming to reduce waste, university students applied conservation techniques and developed new products. These strategies promote the use of excess food in other classes and favor the reduction of the waste rate at the UAN. The results found showed the causes of wasted food at school-kitchen and showed actions to control it, highlighting the relevance of teaching-learning proposals that contribute to innovation and professional training.

Keywords: Food waste; Food integral utilization; Food product development; Materials management.

\section{Resumen}

Las tasas de desperdicio de alimentos en el mundo son elevadas y se producen a lo largo de toda la cadena de producción, incluso en las Unidades de Alimentación y Nutrición (UAN). La cocina-escuela constituye una UAN común a la rutina de enseñanza-aprendizaje para la formación de profesionales relacionados con el área de Alimentos y Bebidas. El presente artículo tuvo como objetivo evaluar el desperdicio de alimentos en una cocina escolar de los cursos de Nutrición y Gastronomía de una universidad pública de Bahía y proponer estrategias para su control. Los alimentos se dividieron en cinco grupos: frutas, verduras, huevos y productos lácteos, carne y productos no perecederos. La recogida de datos se realizó a partir de las planillas de registro de excedentes y de control de temperatura de los equipamientos de los años 2017 a 2019. El total de desperdicio en el periodo evaluado fue de 121,3 $\mathrm{kg}$, siendo el grupo de productos no perecederos el que obtuvo la tasa más alta (media de 19,2 kg/año). Las tres razones principales de los descartes fueron: producto caducado, deteriorado y con un embalaje inadecuado. Los datos del control de los equipos de almacenamiento en frío indicaban una alta variabilidad de la temperatura y un bajo mantenimiento. Para reducir las pérdidas, los estudiantes de la universidad aplicaron técnicas de conservación y desarrollaron nuevos productos, y estas estrategias pueden promover el uso de excedentes en otras clases y permitir la reducción de la tasa de residuos en la UAN. Los resultados encontrados evidenciaron las causas del desperdício en la cocina-escola y presentaron medidas para su control, resaltando la importancia de las propuestas de enseñanzaaprendizaje que vienen contribuyendo a la innovación y formación profesional.

Palabras clave: Desperdicio de alimentos; Aprovechamiento integral de alimentos; Desarrollo de nuevos produtos; Gestión de materiales.

\section{Introdução}

O desperdício de alimentos é um ato proposital consequente dos hábitos culturais e sociais de um povo e permanece como um grave problema mundial, ocorrendo em sistemas alimentares tanto de países desenvolvidos quanto em desenvolvimento (Zaro, 2018; Deliberador, 2019). Estima-se que cerca de 1,3 bilhões toneladas de alimentos sejam desperdiçados mundialmente (Organização das Nações Unidas para a Alimentação e Agricultura, 2017). No Brasil, estes números atingem cerca de 26,3 milhões de toneladas (Organização das Nações Unidas para a Alimentação e Agricultura, 2018), sendo mensurável que o total de alimentos desperdiçados seria suficiente para alimentar toda a população do país.

O Brasil atingiu a oitava posição de maior produtor e exportador de alimentos e apresenta a capacidade de alimentar 7,2 milhões de pessoas em situação de insegurança alimentar (Deliberador, 2019). Este dado alerta para a relevância de adoção de medidas para minimização do desperdício, a exemplo da aplicação de técnicas visando o aproveitamento integral dos alimentos, desenvolvimento de novos produtos com este objetivo, além da criação de banco de alimentos e políticas públicas que favoreçam a doação de insumos alimentícios, desde que atendam aos critérios de segurança alimentar e nutricional, bem como, de segurança de alimentos.

Tais estratégias têm potencial para reduzir substancialmente as taxas de desperdício de alimentos, uma vez que estas são mais representativas no final da cadeia produtiva, notadamente nas etapas de comercialização e de consumo (Zaro, 2018). A etapa de consumo ocorre tanto nos lares e domicílios quanto em Unidades de Alimentação e Nutrição (UAN), as quais englobam os setores de hotelaria, restaurantes comerciais e institucionais, além de catering (Zaro, 2018).

Dentre os restaurantes institucionais, a cozinha escola, o restaurante escola e os restaurantes universitários (RU) constituem UAN fundamentais à rotina de ensino aprendizagem, seja de natureza técnica, profissionalizante ou acadêmica, 
uma vez que tais espaços contribuem para a formação de profissionais relacionados à área de Alimentos e Bebidas (A\&B). Para cursos de graduação em Nutrição e Gastronomia, a cozinha escola promove a responsabilidade de executar preparações, oportunizando o contato com a prática, seja a mesma realizada em momentos distintos das aulas teóricas, de forma intercalada ou, até mesmo, simultaneamente, na própria cozinha, segundo a didática adotada pelo professor para difundir o conhecimento específico (Almeida et al., 2015).

Embora sejam muitas vezes citados como sinônimos em trabalhos acadêmicos, restaurantes escola servem a preparação desenvolvida em cozinhas escola à clientes, enquanto RU distribuem, diariamente, grande quantidade de alimentos à comunidade universitária. Ainda que seja incipiente a quantidade de estudos sobre gestão de restaurantes/cozinhas escola, alguns trabalhos em RU têm sido evidenciados com grandes contribuições para estudos de gestão de UAN institucionais. Em uma pesquisa realizada no RU da Universidade Federal de Uberlândia, por exemplo, foi observado que, de 2.700 refeições disponibilizadas por dia, um total de aproximadamente $2.657,58 \mathrm{Kg}$ de alimentos foram desperdiçados, em 10 dias, nesta UAN. Considerando esse valor, os nutricionistas responsáveis pelo estabelecimento constataram que seria possível alimentar 2.657 pessoas com 2 refeições de 500g para cada (Arantes, 2017).

Sabe-se que os profissionais graduados na área de A\&B, além do conhecimento técnico e prático na produção de alimentos, também devem estar aptos para exercerem uma importante função na gestão de materiais. Assim, o presente estudo tem como objetivo avaliar o desperdício de alimentos em uma cozinha escola dos cursos de Gastronomia e Nutrição de uma universidade pública da Bahia e propor estratégias para este controle.

\section{Metodologia}

Esta pesquisa, de finalidade explicativa, está delineada como um estudo de caso, com o propósito de analisar o panorama atual de desperdício de alimentos em uma cozinha escola (Gil, 2008). Para isso, foram levantados os dados desta UAN relativos às perdas de insumos e, adicionalmente, foram propostas estratégias para minimizar a produção de excedentes. Assim posto, a caracterização da UAN e os métodos aplicados estão descritos a seguir.

\subsection{Caracterização da cozinha escola}

Trata-se de uma cozinha escola que não visa lucro, subsidiada por pregões e licitações burocráticos, e tem como objetivo o ensino aprendizagem com apoio aos cursos de Nutrição e Gastronomia de uma universidade pública da Bahia, Brasil. Quanto aos recursos humanos, 02 servidores técnicos efetivos trabalham nesta UAN, que dão suporte a 29 componentes curriculares práticos, de ambos os cursos, que somam 62 turmas com 363 aulas práticas por semestre. Além destes, 01 servidor está indiretamente ligado à administração da cozinha escola (responsável pelo processo de licitação para aquisição dos insumos utilizados nas aulas práticas), bem como, 16 docentes da instituição (que fornecem a quantidade prevista de cada item adquirido via pregão, para cada componente curricular, durante um semestre). Somam-se a estes, um número variável de discentes que colaboram de forma extracurricular com esta UAN, via Trabalho de Conclusão de Curso (TCC), projetos de pesquisa e extensão, estágio ou monitoria. Os alimentos preparados nesta cozinha escola são desenvolvidos, apresentados e distribuídos para degustação durante as aulas práticas, participando deste processo, exclusivamente, os alunos e docentes dos componentes curriculares.

\subsection{Levantamento de produtos excedentes da cozinha escola}

As planilhas de controle de solicitação de insumos, utilização e descartes de alimentos registradas pelos servidores técnicos efetivos da UAN foram utilizadas para o levantamento dos produtos excedentes. Os insumos alimentícios solicitados 
pela cozinha escola aos fornecedores, de 2017 até 2020, foram divididos categoricamente em cinco grupos alimentares, a saber: (I) frutas; (II) hortaliças; (III) ovos e laticínios; (IV) carnes e (V) não perecíveis (conservas, molhos e condimentos, grãos, enlatados dentre outros alimentos industrializados). Para Silva Júnior (2020), alimentos não perecíveis são aqueles que podem ser armazenados em temperatura ambiente, com suas características mantidas viáveis até o prazo de validade determinado, sendo este o conceito adotado no presente estudo. Posteriormente, foram contabilizadas as quantidades excedentes de cada item registrado nas planilhas de solicitação ao fornecedor (insumos pedidos e entregues à UAN, mas que não foram plenamente utilizados em aulas práticas). Os dados de cada alimento foram padronizados como peso em gramas (g). Por fim, devido à ocorrência da pandemia do Covid-19, as aulas presenciais foram suspensas (março de 2020) e, consequentemente, a aquisição dos insumos para atender aos componentes curriculares também foi suspensa, assim, os registros a partir do ano de 2020 não foram incluídos no estudo.

\subsection{Identificação dos fatores relacionados ao desperdício de alimentos na cozinha escola}

Além da quantidade dos excedentes, foram analisados os registros de controle da cozinha escola relativos às informações de rotina dos produtos para o descarte, conforme o caso (produto fora do prazo de validade, acondicionamento inadequado, entre outros). Este levantamento quali-quantitativo foi representado a partir da frequência de citações dos motivos das perdas nas planilhas de rotina da cozinha escola. De forma complementar, também foi realizada conferência do controle de temperatura dos equipamentos que compõem o estoque frio, junto às planilhas de registros diários. Os parâmetros de temperaturas por tipo de alimento foram fornecidos pela UAN em estudo.

\subsection{Estratégias para o aproveitamento de alimentos e controle de desperdícios na cozinha escola}

Com base nos grupos de alimentos categorizados neste estudo, foram levantadas as técnicas gastronômicas de conservação de alimentos realizadas com o apoio dos discentes os quais, em algum período, colaboraram com a UAN. Possíveis técnicas e preparações potenciais dentro da disponibilidade de equipamentos técnicos na cozinha escola foram, inclusive, investigados. Ressalta-se a expectativa de uso das técnicas verificadas para os produtos excedentes encontrados, visando promover o aumento de sua vida de prateleira e utilização para desenvolvimento de novos produtos, tal qual para ampliar as possibilidades de suporte em insumos junto às aulas práticas da instituição.

\subsection{Análise dos dados}

Os dados foram analisados qualitativa e quantitativamente, sendo os valores encontrados expressos em resultados por porcentagem, média e desvio padrão.

\section{Resultados}

\subsection{Levantamento de produtos excedentes da cozinha escola}

Em relação aos dados dos excedentes dos grupos alimentares da cozinha escola, a Tabela 1 os apresenta, discriminando-os por peso e porcentual, referentes a cada categoria de grupo alimentar. Conforme a Tabela 1, no ano de 2017, o total de desperdício foi, aproximadamente, $41 \mathrm{Kg}$, sendo que os grupos que obtiveram destaque para o desperdício foram: não-perecíveis, hortaliças e frutas, com 39,2\%, 25,8\% e 25,6\% de desperdício por grupo, respectivamente. O grupo que obteve a menor porcentagem de desperdício foi o das carnes, totalizando 3,9\% ( $\approx 1,6 \mathrm{Kg})$. Já no ano de 2018, o total de desperdício foi de cerca de $53 \mathrm{Kg}$, ou seja, um aumento em mais de $20 \%$ do total registrado em 2017. 
Research, Society and Development, v. 11, n. 1, e4411124712, 2022

(CC BY 4.0) | ISSN 2525-3409 | DOI: http://dx.doi.org/10.33448/rsd-v11i1.24712

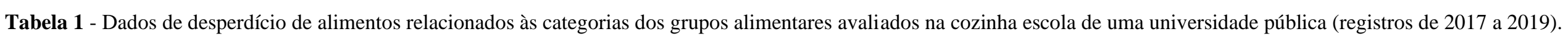

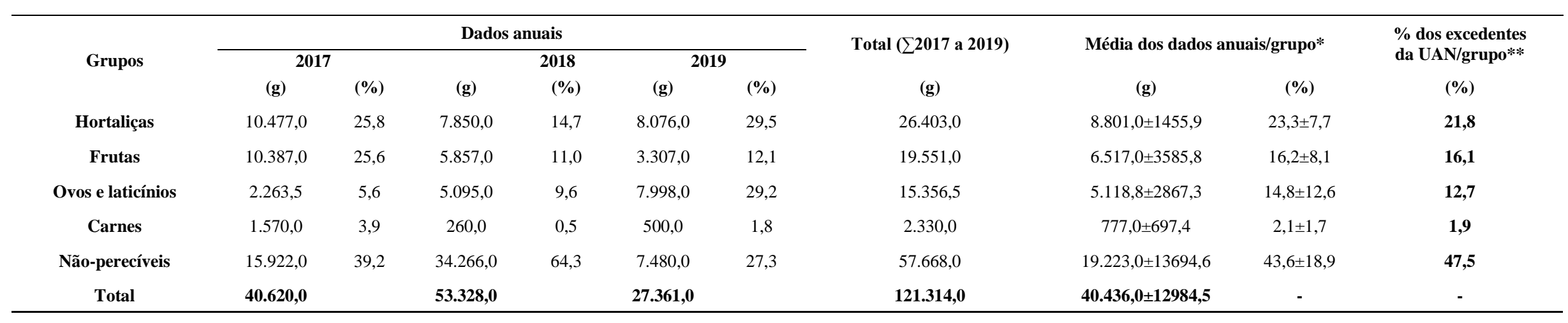

*Média dos registros de 2017 a 2019, por grupo de alimentos. **Percentual representativo em relação ao total médio do peso total (40.436,0g) de alimentos desperdiçados entre 2017 a 2019 , por grupo de alimentos. Fonte: Autores. 
Houve elevação considerável nos números de desperdício no grupo dos não-perecíveis chegando ao valor de 64,3\% e, consequentemente, uma redução nos outros grupos, sendo que o das carnes ainda se manteve com o menor índice, $0,5 \%$ do total.

$\mathrm{O}$ ano de 2019 apresentou o total de desperdício de, aproximadamente, $27,51 \mathrm{Kg}$, com as maiores taxas para os grupos hortaliças, ovos e laticínios e não-perecíveis, com 29,5\%,29,2\% e 27,3\%, respectivamente. Esses valores mostram uma diferença de $0,3 \%$ entre os grupos de hortaliças e ovos e laticínios e uma diferença de $1,9 \%$ entre ovos e laticínios e nãoperecíveis. O grupo de frutas e carnes apresentaram os menores percentuais de perdas, $12,1 \%$ e 1,8\%, respectivamente (Tabela 1).

Em relação aos dados médios anuais de 2017 a 2019, as maiores variabilidades de desperdícios foram identificadas nos grupos dos não-perecíveis e ovos e laticínios, representando um desvio padrão em termos porcentuais de 18,9 e 12,6, respectivamente. A quantidade média anual de alimentos descartados foi de 40,436 $\mathrm{Kg}$, sendo que 47,5\% desse montante correspondeu às perdas de alimentos do grupo dos não-perecíveis (Tabela 1).

Somando-se os três anos avaliados, o total de desperdício foi igual a 121,314 $\mathrm{Kg}$ de alimentos. O grupo dos nãoperecíveis obteve uma soma em torno de $58 \mathrm{Kg}$, sendo o responsável pela maior taxa de desperdício. O grupo das hortaliças ocupou o segundo lugar $(26 \mathrm{Kg}$ ), seguido pelos grupos de frutas, com aproximadamente 19,5 Kg, ovos e laticínios, com cerca de $15 \mathrm{Kg}$, e carnes com uma soma próxima a $2 \mathrm{Kg}$, sendo este o grupo que gerou o menor índice de desperdício em todos os anos analisados (Tabela 1).

\subsection{Identificação dos fatores relacionados ao desperdício de alimentos}

A Figura 1 apresenta os dados anuais da identificação dos fatores relacionados ao desperdício dos alimentos na cozinha escola e a média da frequência destes fatores em relação ao período avaliado.

Ao analisar o ano de 2017, o motivo atribuído à maior incidência foi devido à deterioração do produto, totalizando 36\% (19 vezes) dos registros, e a segunda maior incidência registrada foi devido à perda do insumo por interrupção de energia elétrica, com um percentual de 15\% (8 vezes). Os fatores que obtiveram o menor índice de incidência foram a presença de fungos e o acondicionamento inadequado dos produtos com $6 \%$ (6 vezes) cada um.

Em relação ao ano de 2018, observou-se um percentual de 43\% (47 vezes) para o fato do produto encontrar-se fora do prazo de validade. Em seguida, a devolução de produtos advindos do não uso nas aulas práticas obteve um percentual de $15 \%$ (17 vezes) e as sobras devido ao cancelamento de aulas, em decorrência de eventos internos na instituição, teve uma taxa de $12 \%$ (13 vezes). Os fatores menos recorrentes foram a falta de acondicionamento adequado e danos mecânicos e quebras dos produtos, devido à falha na manipulação, indicando um percentual de $2 \%$ ( 2 vezes), cada um deles.

No ano de 2019, foi possível analisar apenas dois fatores registrados pela UAN, que foram relacionados aos produtos estarem fora do prazo de validade, correspondendo a 10\% (5 vezes) ou deteriorados, $2 \%$ (1 vez). No referido ano, vários insumos foram notificados como descartes nos registros da cozinha escola, porém houve subnotificação de dados por não identificação dos motivos relacionados ao descarte dos produtos, totalizando 88\% (42 vezes). Desse modo, em três anos de estudo, os três principais motivos encontrados para o desperdício de insumos na cozinha escola foram: fora do prazo de validade (45\%, 56 vezes), deterioração (19\%, 23 vezes) e acondicionamento inadequado (13\%, 16 vezes).

Quanto à avaliação específica do acondicionamento em temperatura controlada, a Tabela 2 apresenta os limites de temperaturas registrados nos diferentes equipamentos (refrigeração e congelamento). Observou-se que a maioria das temperaturas registradas estava fora das referenciadas e programadas nos equipamentos. Os equipamentos apresentaram variabilidade elevada entre máximas e mínimas temperaturas registradas, sendo o freezer para produtos congelados, programado para -10 a $-18^{\circ} \mathrm{C}$, o que apresentou maior desvio padrão $( \pm 10,82)$. Ao longo dos três anos avaliados, os 
equipamentos de refrigeração registraram temperaturas inclusive negativas (mínima $-16^{\circ} \mathrm{C}$, em 2019) e os de congelamento mantiveram-se ainda com temperaturas negativas, apesar da alta variabilidade apresentada. Ressalta-se também a necessidade de atualização das referências para controle da temperatura utilizadas pela cozinha escola.

Figura 1 - Frequência dos motivos do desperdício de alimentos na cozinha escola de uma universidade pública. Registros realizados nos anos de 2017 a 2019.

A
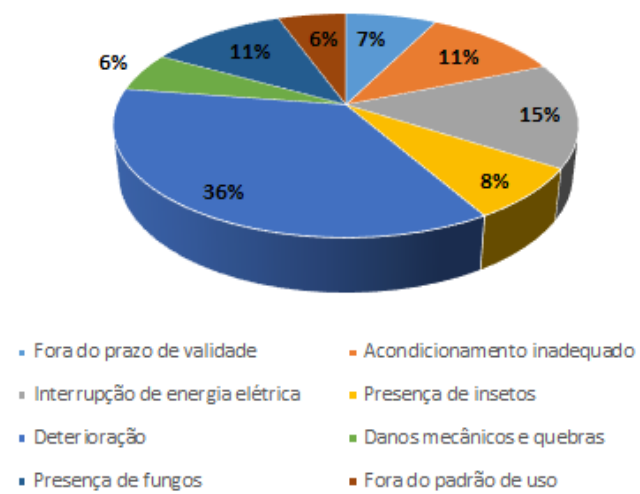

\section{C}

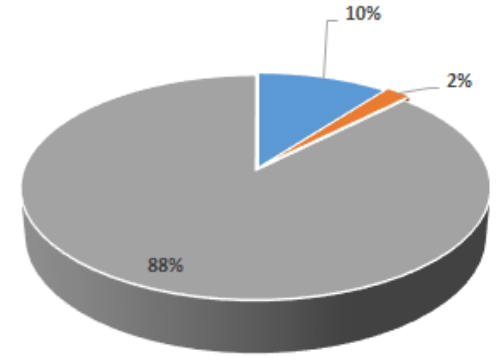

- Fora do prazo de validade - Deter ioração Sem registro

- Fora do prazo de validade - Presença de fungos

- Cancelamento de aulas

- Danos mecânicos e quebras

- Produto não utilizado
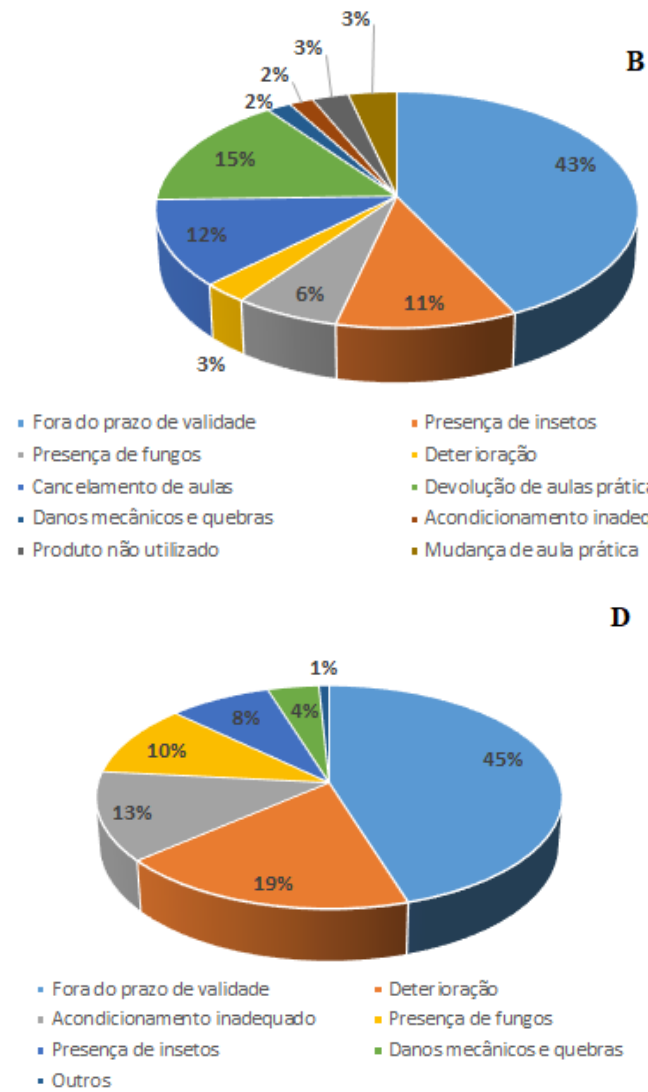

Legenda: A) Dados porcentuais registrados em 2017. B) Dados porcentuais registrados em 2018. C) Dados porcentuais registrados em 2019. D) Média porcentual dos motivos registrados de 2017 a 2019. Total de menção nos registros em número bruto $(\mathrm{n})$ : $\mathrm{A}=53 ; \mathrm{B}=110 ; \mathrm{C}=48$; $\mathrm{D}=124$. Fonte: Autores. 
Tabela 2 - Controle de temperatura dos equipamentos de conservação de alimentos da cozinha escola (registros de 2017 a 2019 ).

\begin{tabular}{|c|c|c|c|c|c|c|c|c|}
\hline \multirow[b]{2}{*}{$\begin{array}{c}\text { Equipamentos para conservação de } \\
\text { alimentos } \\
\left.\text { (faixa de temperatura em }{ }^{\circ} \mathbf{C}\right)^{*}\end{array}$} & \multicolumn{4}{|c|}{ Refrigeração } & \multicolumn{4}{|c|}{ Congelamento } \\
\hline & $\begin{array}{l}\text { Minicâmara para } \\
\text { hortifrúti (8 a 10) }\end{array}$ & $\begin{array}{l}\text { Minicâmara para } \\
\text { laticínios }(6 \text { a 8) }\end{array}$ & $\begin{array}{l}\text { Geladeira } \\
\text { para laticínios } \\
\quad(6 \text { a 8) }\end{array}$ & $\begin{array}{l}\text { Geladeira para } \\
\text { degelo }(<5)\end{array}$ & $\begin{array}{l}\text { Freezer para } \\
\text { produtos } \\
\text { congelados } \\
(-10 \text { a }-18)\end{array}$ & $\begin{array}{l}\text { Freezer } \\
\text { queijos e } \\
\text { laticínios } \\
(-10 \text { a }-18)\end{array}$ & $\begin{array}{l}\text { Freezer suínos, } \\
\text { ovinos e caprinos } \\
(-10 \text { a }-18)\end{array}$ & $\begin{array}{c}\text { Freezer para } \\
\text { peixes inteiros e } \\
\text { filés } \\
(-10 \text { a -18) } \\
\end{array}$ \\
\hline \multirow{8}{*}{$\begin{array}{l}\text { Limites de temperaturas registrados } \\
\text { (mínima à máxima) }\end{array}$} & \multicolumn{8}{|c|}{2017} \\
\hline & -4 a 16 & 2 a 11 & -5 a 8 & -9 a 11 & $-25 \mathrm{a}-11$ & $-29 a-4$ & $-31 \mathrm{a}-4$ & $-24 a-8$ \\
\hline & \multicolumn{8}{|c|}{2018} \\
\hline & NR & 3 a 13 & -4 a 15 & -5 a 9 & $-22 \mathrm{a}-11$ & -20 a -2 & $-28 a-7$ & $-23 a-12$ \\
\hline & \multicolumn{8}{|c|}{2019} \\
\hline & -16 a 14 & NR & -14 a 18 & -16 a 15 & NR & NR & $-27,1$ a -3 & $-27,2$ a $-1,6$ \\
\hline & \multicolumn{8}{|c|}{ Média dos dados anuais } \\
\hline & $8,1 \pm 4,90$ & $3,9 \pm 2,23$ & $-0,1 \pm 4,30$ & $-0,5 \pm 5,22$ & $-17,4 \pm 10,82$ & $-17,5 \pm 6,65$ & $-17,4 \pm 7,23$ & $-18 \pm 3,85$ \\
\hline
\end{tabular}

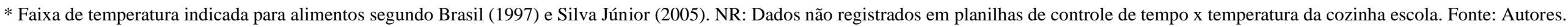




\subsection{Estratégias para o controle de desperdícios na cozinha escola}

Com a tentativa de reduzir a frequência de descartes de alimentos, a cozinha escola apoiou projetos que envolveram a participação de 8 discentes da universidade, sendo 6 participantes de projetos de ações afirmativas da instituição e 2 de estagiários voluntários, os quais iniciaram estudos para a utilização dos insumos excedentes que seriam desprezados, a partir de 2017. Estas técnicas e preparações realizadas estão listadas na Tabela 3, a qual também apresenta descrições de outras possibilidades de uso que podem ser aplicadas para o aproveitamento dos alimentos e extensão do prazo de vida útil dos alimentos da cozinha escola.

Tabela 3 - Técnicas, pré-preparo e preparações básicas realizadas e sugeridas como estratégias para minimizar os descartes de alimentos na cozinha escola.

\begin{tabular}{|c|c|c|c|}
\hline $\begin{array}{c}\text { Grupos } \\
\text { Alimentares } \\
\end{array}$ & $\begin{array}{l}\text { Técnicas de } \\
\text { conservação }\end{array}$ & Preparações realizadas & Alternativas de preparo \\
\hline Hortaliças & $\begin{array}{l}\text { Branqueamento, } \\
\text { congelamento, conservas, } \\
\text { desidratação }\end{array}$ & $\begin{array}{l}\text { Camponata, cebola caramelizada, } \\
\text { fundo de legumes, molhos, polpa de } \\
\text { legumes, ratatouille, temperos, tomate } \\
\text { seco. }\end{array}$ & $\begin{array}{c}\text { Azeites/vinagres aromatizados, manteigas } \\
\text { compostas, marinadas, terrines, confituras, patês e } \\
\text { aperitivos, refogados, recheios, assados, croquetes, } \\
\text { sopas, saladas }\end{array}$ \\
\hline Frutas & $\begin{array}{l}\text { Desidratação, conservas, } \\
\text { cristalização } \\
\text { congelamento }\end{array}$ & $\begin{array}{l}\text { Massa de banana, chutney de abacaxi, } \\
\text { doces, desidratação, geleias, conservas. }\end{array}$ & $\begin{array}{l}\text { Compotas, licores, confituras, bolos, frutas assadas, } \\
\text { caldas, purês, coulis }{ }^{I} \text {, polpas, frutas secas, frutas } \\
\text { cristalizadas, licores e frutas em álcool }\end{array}$ \\
\hline $\begin{array}{l}\text { Ovos e } \\
\text { laticínios }\end{array}$ & Congelamento & Congelamento, doces e pastas & $\begin{array}{l}\text { Pudins, bolos, pães, cremes, massas, caldas, } \\
\text { bombons, mousses e petit fours }{ }^{2}\end{array}$ \\
\hline Carne & $\begin{array}{l}\text { Defumação, desidratação, } \\
\text { secagem e salga }\end{array}$ & $\begin{array}{l}\text { Fundos, defumação, desidratação, } \\
\text { secagem e salga }\end{array}$ & Caldos, molhos, terrines, patês, embutidos \\
\hline $\begin{array}{l}\text { Não- } \\
\text { perecíveis }\end{array}$ & $\begin{array}{l}\text { Congelamento e } \\
\text { desidratação }\end{array}$ & $\begin{array}{l}\text { Congelamento, desidratação, } \\
\text { elaboração de farináceos, }\end{array}$ & $\begin{array}{l}\text { Sementes desidratadas, farinhas de grãos, mistura } \\
\text { de farináceos, petitfours }{ }^{2} \text {, massas, pastas, } \\
\text { aperitivos, produtos de panificação, pães, bolos }\end{array}$ \\
\hline
\end{tabular}

${ }^{1}$ Produto altamente concentrado oferecido na forma de purê ou líquido (Instituto Americano de Culinária, 2014); ${ }^{2}$ Designação dada a produtos elaborados em pequenas dimensões, como biscoitos, sequilhos, bolinhos ou tortinhas (Sebess, 2014). Fonte: Autores.

Em uma perspectiva temporal, no ano de 2017, houve apenas um discente responsável pelo aproveitamento dos insumos, o que resultou em 3 pré-preparos/preparações elaborados, a partir dos excedentes, que foram dois tipos de fundos (legumes e peixes) e biomassa de banana. Já em 2018, o número de discentes envolvidos no projeto foi de 4, o que possibilitou o aumento das técnicas e pré-preparos/preparações, somando-se um total de 15 tipos, como por exemplo a aplicação de branqueamento e desidratação e a elaboração de fundos, conservas, molhos, chutney de abacaxi, temperos, dentre outros. No ano de 2019, apenas 3 discentes deram continuidade ao projeto e houve uma sensível queda de técnicas/preparações elaboradas totalizando-se 7, sendo algumas delas a produção de fundos, doces de frutas, molhos e conservas (Tabela 3).

\section{Discussão}

A análise dos principais fatores de descarte de insumos da cozinha escola, infere que estar fora do prazo de validade foi o mais recorrente, presente nos três anos consecutivos, representando $45 \%$ do total (Figura 1-D). Comparando os dados analisados com os grupos alimentares excedentes (Figura 1-A e Tabela 1), é perceptível que no ano de 2017 os grupos de hortaliças e frutas, quando somados, geraram a maior quantidade de insumos desperdiçados, corroborando com os motivos de descarte como deterioração, acondicionamento inadequado e interrupção de energia elétrica, que ocorreu no período. Desta forma, por serem mais perecíveis e não terem sido mantidos em armazenamento adequado, tais produtos apresentaram os maiores índices de desperdício deste ano. 
Assim como em 2017, porém com valores visivelmente mais elevados, no ano de 2018, o grupo de não-perecíveis (Tabela 1) apresentou maior taxa de desperdício, corroborando com os motivos elencados para este mesmo ano, ou seja, perda do prazo de validade dos produtos (Figura 1). No ano de 2019, os grupos de hortaliças, ovos e laticínios e não-perecíveis, foram os que obtiveram as maiores taxas de desperdício, mas não foi possível identificar com maior precisão os reais motivos de tais descartes. Isso ocorreu devido ao fato da maioria dos insumos não ter sido contabilizada juntamente com a justificativa do descarte, implicando na dificuldade de interpretação devido à subnotificação.

As perdas por estar fora do prazo de validade foram as mais recorrentes na cozinha escola (Figura 1). Neste sentido, a rotatividade é um controle importante para evitar que os produtos ultrapassem esse tempo, pois ao serem utilizados até perto da data de vencimento, o número de desperdício desse grupo poderia reduzir de forma impactante (Spagnol et al., 2014).

Sendo assim, é importante destacar que a cozinha escola já possui essa ferramenta de controle (PVPS- Primeiro que Vence, Primeiro que Sai). Além disso, existe um controle de validade para os produtos que são recebidos. Os produtos fornecidos são entregues com o prazo de validade estabelecido no termo de referência do pregão. Laticínios, bebidas, produtos de confeitaria, cereais e derivados apenas são recebidos com o prazo de validade superior a 120 dias ou dentro da metade do prazo de validade total referido pelo fornecedor, contados da data do recebimento. Os produtos referentes a hortifrutigranjeiros, como os ovos, são recebidos com 30 dias de validade; as carnes refrigeradas têm o prazo de 60 dias, as salgadas de 120 dias e as congeladas de 1 ano de validade, contados a partir da data da entrega.

Vale ressaltar que, na rotina da cozinha escola, os alimentos próximos a expirar a data de validade são divulgados via e-mail aos docentes, para que avaliem a possibilidade de incremento de preparações que utilizem os insumos, evitando perdas. No entanto, esta alternativa de utilização nem sempre é possível. Em adição, há alguns casos em que os fornecedores apresentam limite de quantidade mínima para o fornecimento de alimentos, o que incide em um recebimento maior do que o necessário para as aulas. Desta forma, destaca-se a necessidade da adoção de outras estratégias para aproveitamento e conservação dos alimentos, uma vez que há situações de logística interna da UAN que se sobrepõem às ferramentas de gestão disponíveis.

Os produtos in natura não apresentam prazo de validade pré-estabelecido para serem recebidos, necessitando, desta forma, da inspeção das características de integridade durante a recepção dos mesmos e da manutenção destes produtos em temperaturas controladas. Neste aspecto, ressalta-se que outro fator de importante análise de motivos de desperdício é o controle de temperatura dos equipamentos de conservação da cozinha escola.

Segundo Ricarte (2008), para reduzir as perdas na qualidade dos alimentos ao mínimo, deve-se observar e manter condições satisfatórias de controle de temperatura da UAN. Foi observado que os equipamentos da cozinha escola apresentam manutenção limitada das temperaturas programadas (Tabela 2) e isso implica em perdas de determinados alimentos que exigem temperatura controlada durante sua vida útil, especialmente de frutas e hortaliças. Levando isso em consideração, a variabilidade de temperaturas apresentadas nos equipamentos analisados pôde ter contribuído para que os grupos das hortaliças e frutas fossem o segundo e terceiro maiores em desperdício (Tabela 1). Ressalta-se que, considerando que estes grupos alimentares configuram produtos cujas quantidades mínimas entregues pelos fornecedores tendem a ser superiores àquelas solicitadas, o excesso dos mesmos não raro causa a sobrecarga dos equipamentos responsáveis pela conservação sob refrigeração, que por sua vez, leva à variabilidade de temperatura acima do recomendado para a conservação de frutas e hortaliças (Tabela 2). Esse fator explica também o fato do descarte de maior índice ser devido aos alimentos estarem deteriorados (Figura 1).

Por outro lado, o grupo de carnes foi o que apresentou as menores taxas de perdas (Tabela 1), apesar de também necessitar de temperatura controlada. No entanto, apesar da variabilidade de temperaturas nos equipamentos, os freezers utilizados para acondicionamento de carnes são programados para o congelamento e ainda mantiveram temperaturas negativas 
como máximas registradas, permitindo que estes produtos ainda permanecessem congelados. Além disso, a UAN adquire e requisita quantidades menores deste tipo de insumo em relação aos demais, e isso pode facilitar a organização, manejo e supervisão dos mesmos, minimizando assim as perdas. Todas estas condições, portanto, corroboraram para os melhores resultados terem sido encontrados para este grupo.

Adicionalmente à utilização prioritária de alimentos perto do vencimento e à manutenção periódica de equipamentos, é importante a implementação de outras medidas de controle para minimizar as perdas, como a realização de técnicas de conservação e preparações básicas que possam ser incorporadas às dinâmicas das aulas práticas dos componentes da instituição. Ao analisar uma possibilidade para a redução do número de desperdício, os discentes que participaram dos programas de bolsas utilizaram técnicas gastronômicas para desenvolver novos produtos e preparações a partir de excedentes (Tabela 3). Isso permitiu que os alimentos fossem destinados a outras aulas na universidade e minimizou o desperdício pelo aproveitamento dos mesmos, como observado especialmente para os grupos de hortaliças, frutas e carnes do ano de $2018 \mathrm{em}$ comparação com o ano de 2017 (Tabela 1).

Nesta perspectiva, o estudo de Reis et al. (2017) demonstrou que a desidratação de frutas para a fabricação de farinhas aumentou o tempo de vida útil das mesmas para 75 dias, sendo esta técnica implementada pelo apoio discente que contribuiu para a redução do desperdício na cozinha escola em estudo, a exemplo da fabricação de temperos. Portanto, a ação realizada pelos discentes é de grande importância para redução de custos na universidade e iniciativas de inovação na área de A\&B, com relação numérica direta entre envolvidos e resultados alcançados (ou seja, quanto maior o número de alunos, mais técnicas/preparações são implementadas na UAN), evidenciando-se a necessidade de implantação de políticas internas que promovam a manutenção dessas atividades.

Os produtos desenvolvidos foram destinados ao preparo de diversos pratos (Tabela 3). Embora não se tenha um registro quantitativo de levantamento desses dados, sabe-se que há uma considerável variedade de usos empregados no desenvolvimento dos componentes curriculares, além de outras possíveis sugestões para utilização destes produtos (Tabela 3). Com o fortalecimento dessa ação, seria possível constituir receituário fixo (contemplando fichas técnicas padronizadas) para dar apoio à cozinha escola, sendo o desenvolvimento de tal material capaz de subsidiar cursos de extensão junto à comunidade, contribuindo para a relação desta com a universidade e, assim, favorecendo a redução do desperdício doméstico. Tais atividades poderiam constituir trabalho multidisciplinar entre os cursos de Nutrição e Gastronomia, contribuindo para a sensibilização e complementação da formação discente, no sentido de promover a importância em se compreender as responsabilidades sociais inerentes à sua formação profissional, respondendo-as com ética e comprometimento (Silva et al., 2021).

Desta forma, o estímulo ao empreendedorismo também deve ser avaliado: promovendo, por exemplo, a criação de uma mistura de farinhas para preparar um bolo prático, saboroso e saudável ou testando novos sabores e combinações de boa aceitação e com aplicabilidade na gastronomia. Neste contexto, atividades de pesquisa, visando à iniciação científica e tecnológica, podem contribuir ainda mais para o potencial destas atividades, ao focar no desenvolvimento de novos produtos e/ou trabalhando estratégias gerenciais de uma UAN. Ressalta-se, neste aspecto, que o aproveitamento de alimentos serve para promover a redução do desperdício e pode ser uma alternativa para a complementação da dieta e redução de custos na UAN (Bressiani et al., 2017), de forma que a tríade ensino, pesquisa e extensão reverbera o potencial da cozinha escola como campo de atuação e é capaz de indicar meios para se atingir esses objetivos.

Iniciativas que estimulam o ensino aprendizagem na rotina de formação discente têm sido evidenciadas na literatura. Nascimento (2019), ao elencar as razões alegadas pelos discentes da Escola Técnica Estadual de Santa Ifigênia (na cidade de São Paulo) que abandonaram seus cursos, observou que, dentre as justificativas mencionadas, falta de recursos financeiros e dificuldades enfrentadas na resolução de problemas interpessoais foram relatadas. 
Desta forma, considerando que as atividades extracurriculares que fomentam a participação do alunado na rotina da cozinha escola do presente estudo aproximam o discente do docente - estreitando essa relação e, consequentemente, fortalecendo o interesse em dar continuidade aos estudos -, bem como, geralmente subsidiam o trabalho desenvolvido com bolsas de estudo, tais atividades podem contribuir para a manutenção do discente na universidade. Em adição, essa prática contribui para a atualização de conhecimentos, não apenas acadêmicos, mas também acerca de questões sobre a gastronomia sustentável, viés contemporâneo que vem valorizando a utilização de alimentos naturais, a redução no desperdício de alimentos e a promoção de benefícios ao meio ambiente e na qualidade de vida das pessoas (Lopes et al., 2019; Correia Júnior et al., 2021).

Além disso, considera-se necessário obter uma regularidade e estabilidade nas temperaturas de conservação, sendo uma das prioridades, pois mesmo com as técnicas para aumentar a vida de prateleira, o acondicionamento adequado é de extrema importância. Há uma necessidade de maior assistência à cozinha escola, devido à instabilidade de atividades desenvolvidas/inconstância de recebimento de pedidos junto ao fornecedor (problemas comuns da administração pública, no sentido de se estabelecer fornecedores, quantitativo de insumos solicitados e manutenção de fornecimento via pregão). Como exemplo, destaca-se que a falta de insumos básicos para a preparação das receitas previstas no planejamento didático do componente gera a impossibilidade da execução das mesmas, fazendo com que os insumos complementares, que seriam utilizados nessas produções, sejam devolvidos à cozinha escola, o que gera um aumento no índice de desperdício.

Neste sentido, devido à tais inconstâncias, que extrapolam os planejamentos realizados (dos servidores da cozinha escola aos docentes que a utilizam), o apoio dos discentes é fundamental para melhorar o controle do desperdício. Isto contribui para manutenção mais detalhada dos registros de rotina, para o desenvolvimento dos produtos com benefício para outras aulas práticas e, além disso, estimula o empreendedorismo, a criação e a inovação durante a formação discente.

\section{Considerações Finais}

Com base nos dados avaliados, a quantidade de alimentos descartados na cozinha escola foi elevada, com maior porcentual para os alimentos não perecíveis. Os principais fatores que condicionam esta situação são referentes aos alimentos fora do prazo de validade, ao acondicionamento inadequado e à deterioração. Desta forma, a manutenção regular dos equipamentos de temperatura controlada, a adoção de técnicas de conservação e formas de pré-preparo e preparações, para o aproveitamento de alimentos e extensão da vida útil, além da implantação de iniciativas que contribuam para o registro dos dados de maneira mais eficiente (estabelecimento de protocolos sistematizados de controle e apoio na tabulação de dados), são relevantes para minimização das perdas. A manutenção de projetos que envolvam a colaboração de discentes para adoção e aplicação das técnicas e/ou preparações é uma forma de intervenção que pode sustentar o objetivo de reduzir perdas, além de representar uma importante estratégia na dinâmica de ensino aprendizagem em cursos de A\&B. Os resultados encontrados evidenciaram as causas das perdas na cozinha escola e apresentaram medidas para seu controle, ressaltando a importância de propostas de ensino aprendizagem capazes de contribuir para a formação profissional.

Vale ressaltar que este estudo pode ser considerado inovador, uma vez que há carência de informações sobre a logística e gestão de materiais em cozinhas escolas institucionais. Portanto, acredita-se que este trabalho é de grande contribuição para a sociedade, ao proporcionar conteúdo relevante para futuras pesquisas sobre o tema. Neste aspecto, sugerese o aprofundamento das questões relacionadas ao fluxo de insumos, de forma a compreender o levantamento e análise do total solicitado via pregão, a quantidade realmente entregue e o volume desperdiçado na UAN, dando maior subsídio ao entendimento sobre as especificidades e limitações dos procedimentos licitatórios. Além disso, indica-se o estudo comparativo e de viabilidade relativo à inserção de metodologias, técnicas, procedimentos que contribuam para melhor controle da gestão, 
considerando o perfil característico de cozinhas escolas institucionais. Por fim, recomenda-se catalogar projetos realizados neste tipo de UAN (sejam eles de ensino, pesquisa ou extensão) que visem a redução do desperdício, publicizando e enaltecendo ações desta natureza e promovendo maior integração junto à sociedade, uma vez que trata-se de tema pertinente a toda população.

\section{Referências}

Almeida, I. O., Salazar, V. S. \& Leite, Y. V. P. (2015). Processo de ensino e aprendizagem do profissional de cozinha: didática do saber técnico e o restaurante-escola. Observatório de Inovação do Turismo - Revista Acadêmica, IX(1), 28-51.

Arantes, C. A. (2017). Desperdício de alimentos e geração de resíduos sólidos biodegradáveis no restaurante universitário do campus Santa Mônica da Universidade Federal de Uberlândia/MG. Periódico Técnico e Científico Cidades Verdes, 5(11), 1-14.

Brasil. Portaria n 326 - SVS/MS, de 30 de julho de 1997. (1997) Regulamento Técnico sobre as Condições Higiênico - Sanitárias e de Boas Práticas de Fabricação para Estabelecimentos Produtores / Industrializadores de Alimentos. https://www.gov.br/agricultura/pt-br/assuntos/inspecao/produtosvegetal/legislacao-1/biblioteca-de-normas-vinhos-e-bebidas/portaria-no-326-de-30-de-julho-de-1997.pdf/view.

Bressiani, J., Schwarz, K., Gatti, R. R., Demário, R. L. \& Freire, P. L. I. (2017). Desperdício Alimentar X Aproveitamento Integral de Alimentos: Elaboração de Bolo de Casca de Banana. Uniciências, 21(1), 39-44.

Correia Júnior, C. A., Oliveira, I. M. de., Sousa, J. L. C. de., Nascimento, N. V. do. \& Melo, F. S. N. de. (2021). Sustentabilidade na gastronomia contemporânea. Research, Society and Development, 10(9), 1-6.

Deliberador, L. R. (2019). Desperdício de alimentos em restaurantes: uma análise em uma instituição universitária. [Dissertação, Universidade Federal de São Carlos]. https://repositorio.ufscar.br/handle/ufscar/11042.

Gil, A. C. (2008). Métodos e Técnicas de Pesquisa Social. (6a ed.). Atlas.

Instituto Americano de Culinária. (2014). Garde Manger: a arte e o ofício da cozinha fria. (4a ed.). Senac.

Lopes, C. B., Guerra, I. C. D., Oliveira, M. G. Q. \& Brito, E. V. S. (2019). Gastronomia sustentável: aproveitamento da polpa de coco verde como alternativa de geração de renda. Applied Tourism, 4(2), 19-24.

Nascimento, H. S dos. (2019). Desistência de Curso Técnico em Cozinha: razões alegadas pelos alunos. [Dissertação, Pontifícia Universidade Católica de São Paulo]. https://sapientia.pucsp.br/handle/handle/22754.

Organização das Nações Unidas para a Alimentação e Agricultura - FAO. (2017). Seminário reúne especialistas do Brasil e da Europa para o debate sobre perdas e desperdicio de alimentos. http://www.fao.org/brasil/noticias/detail-events/pt/c/1053836/.

Organização das Nações Unidas para a Alimentação e Agricultura - FAO. (2018). Semana nacional de conscientização da perda e desperdício de alimentos. <http://www.fao.org/brasil/noticias/detail-events/pt/c/1163036/>.

Reis, D. S., Figueiredo Neto, A., Ferraz, A. V. \& Freitas S. T. (2017). Produção e estabilidade de conservação de farinha de acerola desidratada em diferentes temperaturas. Brazilian Journal of Food Technology, 20, 1-7.

Ricarte, M. P. R., Fé, M. A. B. M., Santos, I. H. V. S. \& Lopez, A. K. M. (2008). Avaliação do desperdício de alimentos em uma Unidade de Alimentação e Nutrição institucional em Fortaleza-CE. Saber Científico, 1(1), 158-175.

Sebess, M. (2014). Técnicas de Confeitaria Profissional. (3a ed.). Senac.

Silva, T. T. C. da., Lacerda, E. C. Q., Tavares, L. F., Cardozo, T. S. F., Bitar, N. P. \& Accioly, E. (2021). A Extensão Universitária no Instituto de Nutrição Josué de Castro da Universidade Federal do Rio de Janeiro. Demetra: Alimentação, Nutrição \& Saúde, 16, 1-10.

Silva Júnior, E. A. da. (2005). Manual de Controle Higiênico Sanitário em Alimentos. (6a ed.. Livraria Varela.

Silva Júnior, E. A. da. (2020) Manual de Controle Higiênico-Sanitário em Serviços de Alimentação. (8a ed.). Livraria Varela.

Spagnol, W. A., Silveira Junior, V., Pereira, E. \& Guimarães Filho, N. (2018). Redução de perdas nas cadeias de frutas e hortaliças pela análise da vida útil dinâmica. Brazilian Journal of Food Technology, 21, 1-10.

Zaro, M (2018). Desperdício de alimentos: velhos hábitos, novos desafios. Educs. 